\title{
A genome-wide association study identifies a novel locus on chromosome 18q12.2 influencing white cell telomere length
}

\author{
M Mangino, ${ }^{1}$ J B Richards, ${ }^{1,2}$ N Soranzo, ${ }^{1,3}$ G Zhai,, A Aviv, ${ }^{4}$ A M Valdes, ${ }^{1}$ N J Samani, \\ P Deloukas, ${ }^{3}$ T D Spector ${ }^{1}$
}

${ }^{1}$ Department of Twin Research and Genetic Epidemiology, King's College London, London, UK; ${ }^{2}$ Department of Medicine, Jewish General Hospital, Faculty of Medicine, McGill University,

Montréal, Québec, Canada;

${ }^{3}$ Wellcome Trust Sanger Institute, Wellcome Trust Genome Campus, Hinxton, UK; ${ }^{4}$ Centre of Human Development and Aging, New Jersey Medical School, Newark, New Jersey,

USA; ${ }^{5}$ Department of Cardiovascular Sciences, University of Leicester, Leicester, UK

Correspondence to: Professor T D Spector Department of Twin Research \& Genetic Epidemiology, King's

College London, St Thomas Hospital Campus, Lambeth Palace Road, London SE1 7EH, UK; tim.spector@kcl.ac.uk

$\mathrm{MM}$ and JBR contributed equally to this work

Received 18 November 2008 Revised 18 January 2009 Accepted 6 February 2009 Published Online First 24 April 2009

\section{ABSTRACT}

Background: Telomere length is a predictor for a number of common age related diseases and is a heritable trait. Methods and results: To identify new loci associated with mean leukocyte telomere length we conducted a genome wide association study of 314075 single nucleotide polymorphisms (SNPS) and validated the results in a second cohort ( $\mathrm{n}$ for both cohorts combined $=2790$ ). We identified two novel associated variants (rs2162440, $p=2.6 \times 10^{-6}$; and rs7235755,

$p=5.5 \times 10^{-6}$ ) on chromosome $18 q 12.2$ in the same region as the VPS34/PIKC3C gene, which has been directly implicated in the pathway controlling telomere length variation in yeast.

Conclusion: These results provide new insights into the pathways regulating telomere homeostasis in humans.

Telomeres are nucleoprotein structures capping and protecting the ends of chromosomes. Because of the "end replication problem", ${ }^{1}$ telomeres shorten with each cell division and leucocyte telomere length has been shown to decrease with age at a rate of 20-40 base pairs per year. ${ }^{23}$ Telomere attrition is enhanced by inflammation and oxidative stress and short telomere length is an independent predictor of age related diseases such as hypertension, myocardial infarction, congestive heart failure, vascular dementia, osteoporosis, osteoarthritis and Alzheimer's disease. ${ }^{3}$

There is wide inter-individual variability in telomere length at birth and at subsequent ages. Both twin studies and intra-familial correlation analysis have identified a genetic influence (from $40 \%$ to $80 \%$ ) on telomere length variation. ${ }^{45}$ Genome-wide linkage studies have mapped OTLs for this trait to chromosomes $12 \mathrm{q} 12.22^{5}$ and 14q23.2. ${ }^{4}$ More recently Mangino et $a l^{6}$ refined the chromosome 12q12.22 locus and described an associated polymorphism (rs2630778) in the BICD1 gene. To date, none of these findings have been replicated, possibly due to difficulties in measuring this trait in a large number of samples and due to lack of high correlation between the methods used to measure telomere length.

Genome-wide association (GWA) analysis is a powerful tool for unlocking the genetic basis of complex traits and has recently provided novel insights into the genetic architecture of many common diseases and traits. ${ }^{78}$ We therefore undertook a GWA scan to identify common alleles that may influence telomere length. Our findings indicate that single nucleotide polymorphisms
(SNPs) rs2162440 and rs7235755 on chromosome 18q12.2 are associated with short telomere length in two independent datasets of European descent.

\section{METHODS}

We conducted a two stages GWA study on 2790 individuals from the UK Adult Twin Register (table 1), in which we evaluated 314075 SNPs. The design and methodology of the GWA study is described in detail elsewhere. ${ }^{7}$ In brief, the discovery sample consisted of 1625 women from the St Thomas' UK Adult Twin Registry, a a large cohort of twins historically developed to study the heritability and genetics of diseases with a higher prevalence among women. The sample is not enriched for any particular disease or trait and is representative of the British general population. ${ }^{4}$ The replication cohort included 1165 subjects of both genders (table 1) from the UK Twin Registry who were unrelated to the individuals from the discovery sample.

Leucocyte telomere length (LTL) was derived by using Southern blot analysis in duplicate to measure the mean terminal restriction fragment. ${ }^{10}$ The coefficient of variation for this measurement was $1.5 \%$. Because all the individuals of the discovery cohort were females, telomere length was only adjusted for age. After adjustment, the trait was normally distributed in the sample.

Genomic DNA was subjected to SNP genotyping via the Infinium assay (Illumina, San Diego, California, USA), using three fully compatible BeadChip microarrays (HumanHap300-Duo,

Table 1 Characteristics of the 2790 individuals assessed for telomere length variation

\begin{tabular}{|c|c|c|c|}
\hline & $\begin{array}{l}\text { Twins UK } \\
\text { discovery } \\
\text { cohort }\end{array}$ & $\begin{array}{l}\text { Replication } \\
\text { cohort }\end{array}$ & $\begin{array}{l}\text { Total } \\
\text { sample }\end{array}$ \\
\hline $\begin{array}{l}\text { Subjects } \\
\text { assessed for TRF }\end{array}$ & 1625 & 1165 & 2790 \\
\hline Age (years)* & $47.9(12.6)$ & $49.2(13.6)$ & $48.5(13.1)$ \\
\hline Males* & - & $48.1(13.8)$ & 48.1 (13.8) \\
\hline Females* & $47.9(12.6)$ & 49.5 (13.5) & $48.5(13.0)$ \\
\hline Sex & - & 264 & 264 \\
\hline Males & 1625 & 901 & 2526 \\
\hline \multicolumn{4}{|l|}{ Females } \\
\hline $\mathrm{LTL}^{*}$ & $7.02(0.67)$ & $6.91(0.68)$ & $6.97(0.68)$ \\
\hline Males* & - & $6.68(0.69)$ & $6.68(0.69)$ \\
\hline Females* & $7.02(0.67)$ & $6.98(0.66)$ & $7.01(0.67)$ \\
\hline
\end{tabular}

LTL, leucocyte telomere length.

*Values presented as mean (SD). 


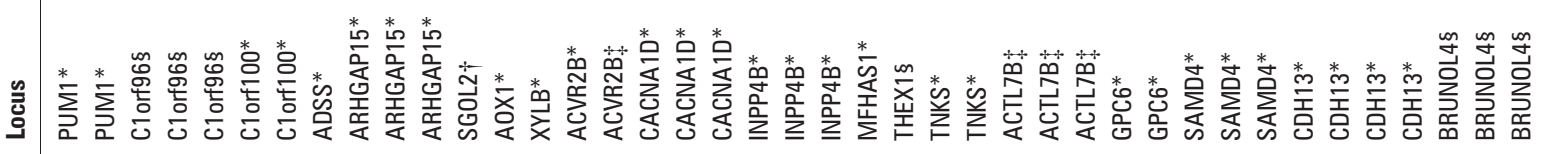

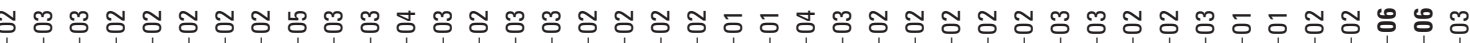

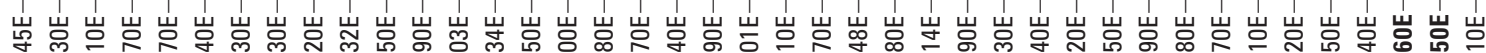

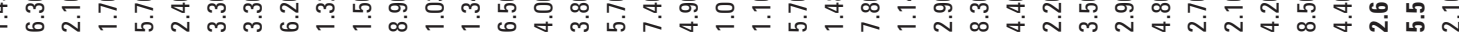

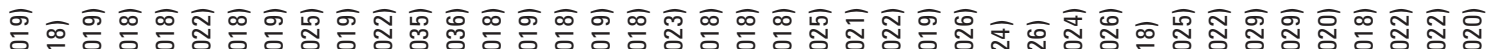

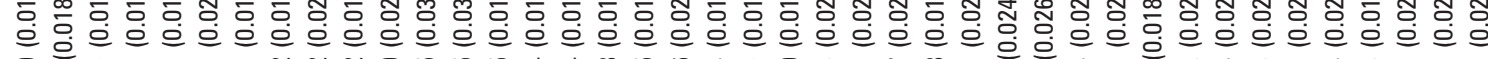

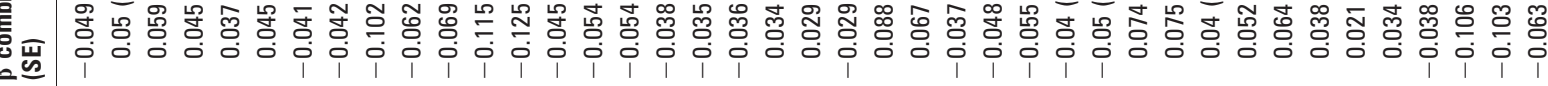

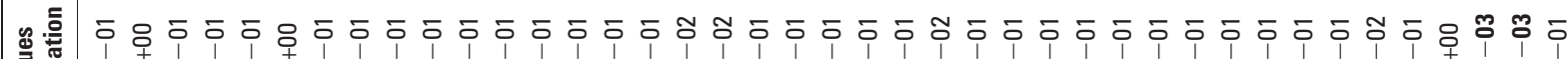

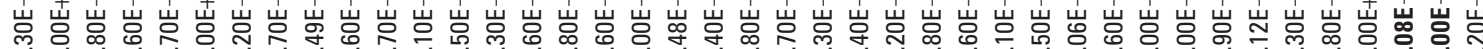

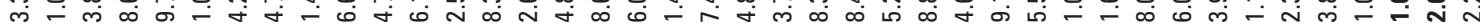

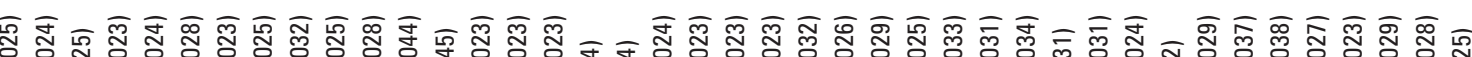

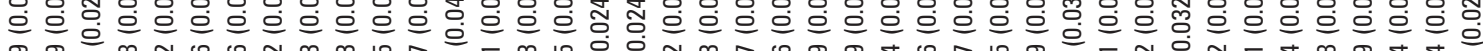

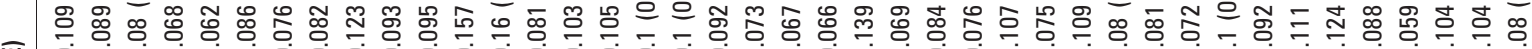

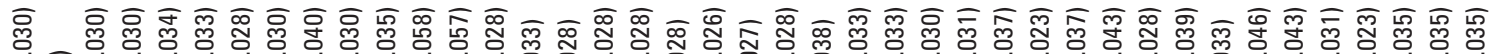

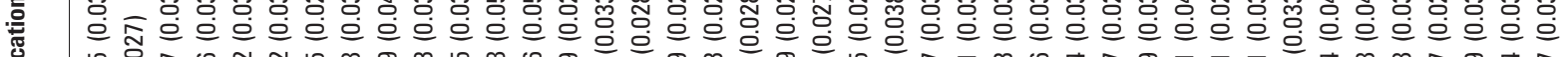

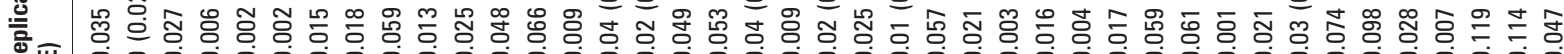

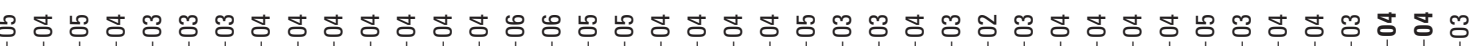

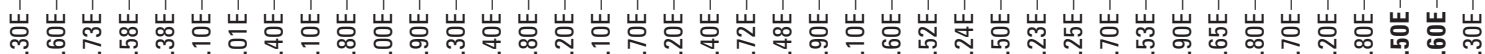
=

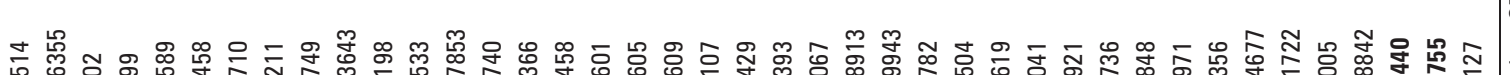
管 
HumanHap300 and HumanHap550), according to the manufacturer's protocols.

We excluded 733 SNPs that had a low call rate ( $\leqslant 90 \%), 2704$ SNPs that had Hardy-Weinberg $p$ values $<10^{-4}$, and 725 SNPs with minor allele frequencies $<1 \%$. We also removed subjects where genotyping failed for $>2 \%$ of SNPs. We retained for the analysis $98.7 \%$ (314 075) of all available SNPs. Statistical analysis was carried out with MERLIN (version 1.1.2) ${ }^{11}$ using the score test (-fastAssoc), while accounting for family structure and twin zygosity. ${ }^{12}$

\section{RESULTS}

In the discovery sample $(\mathrm{n}=1625)$ the strongest association was recorded for rs 7374458 on chromosome $3\left(5.20 \times 10^{-6}\right)$. We also identified 28 SNPs with a $p$ value of $\leqslant 10^{-4}$ and 316 SNPs with a $p$ value of $\leqslant 10^{-3}$. We visually inspected all the signal intensity plots of these SNPs and excluded the markers that had been miscalled (11.3\%).

Since none observed $\mathrm{p}$ values reached a genome-wide significance level after correcting for multiple testing, we adopted the conservative approach of selecting for replication only those polymorphisms with a $p$ value $<10^{-3}$ that were $\approx 100 \mathrm{~Kb}$ from other associated SNPs $\left(p \leqslant 1.0 \times 10^{-2}\right)$. Following these criteria, we identified 15 associated loci including a total of 41 SNPs with the $p$ values for the lead SNPs ranging from $5.20 \times 10^{-6}$ to $9.7 \times 10^{-4}$ (table 2 ).

These 41 selected SNPs were genotyped in the replication cohort $(\mathrm{n}=1165)$ using Sequenom iPLEX (San Diego, California, USA) technology. Because the replication cohort included both males and females, LTL values were adjusted for both gender and age. After adjustment the trait was again normally distributed. To control for multiple testing, we used an SNP spectral decomposition method proposed by Nyholt ${ }^{13}$ and modified by Li and Ji. ${ }^{14}$ After spectral decomposition of the linkage disequilibrium (LD) matrices of the 41 analysed SNPs, the corrected threshold of statistical significance in the replication stage was estimated at $p \leqslant 2.1 \times 10^{-3}$ which is a conservative correction for the number of independent SNPs tested in the replication sample. The results of the association analysis are reported in table 2 and show that we were able to replicate the association observed in the GWA sample for two markers, rs2162440 and rs7235755, both mapping to a $2.2 \mathrm{~Kb}$ region of chromosome 18q12.2.

Since the discovery cohort included only females, we also performed a gender specific analysis on the replication population in order to test if the genetic variants may be associated with telomere lengths only for females. The result showed that for both SNPs the direction of the trend was consistent between genders in the replication cohort (rs2162440: -100 (44) base pairs (bp) for females and -140 (70) bp for males; rs7235755 -94 (42) bp for females and -138 (71) bp for males) and between females of the two cohorts (rs2162440: -104 (29) bp for female in discovery and -100 (44) bp for females in replication; rs7235755 -104 (28) bp for female in discovery and -94 (42) bp for females in replication). Although borderline (due to small sample size), $\mathrm{p}$ values were statistically significant for both SNPs in both genders in the replication cohort (rs2162440: females $p=0.012$, males $p=0.046$; rs7235755: females $p=0.02$, males $p=0.049$ ).

The joint analysis of genotyped data from the two cohorts yielded combined $p$ values of $2.60 \times 10^{-6}$ (rs2162440) and $5.50 \times 10^{-6}$ (rs7235755). Our analysis also indicated that the G alleles of both SNPs were associated with shorter telomeres (-106 (22) bp for rs2162440 and -103 (22) bp for rs7235755), extrapolating to an approximate 5 years of telomere erosion based on estimates of loss with age.

\section{DISCUSSION}

Although our results are unlikely to be artefacts because the identified SNPs were replicated in two independent cohorts, we do believe that our power for identifying association was reduced by the known limitations of the measurement technique. ${ }^{15}$ Therefore, we can only detect common variants. Indeed, it is likely that there are more loci with small genetic effect that we did not detect because of the stringent thresholds for statistical significance employed in this study. This would explain why we did not detect loci such as those previously identified on chromosome 12q12.22 and 14q23.2.

According to NCBI build 36 , the associated polymorphisms map to a $48 \mathrm{~Kb} \mathrm{LD}$ block within a gene desert, between the Bruno-like 4 (BRUNOL4, NM_020180) and VPS34 (also known as PIK3C3, NM_002647) genes. The identified SNPs (or another variant present in the $\mathrm{LD}$ block) might be influencing the expression of either transcript through long range control, as has been demonstrated for other genes. ${ }^{16}$ This hypothesis is supported by the observation that the associated $48 \mathrm{~Kb} \mathrm{LD}$ block lies in a highly conserved genomic segment. The two associated variants map $\sim 70 \mathrm{~Kb}$ away from BRUNOL4 and $4.3 \mathrm{Mb}$ away from VPS34. BRUNOL4 is a member of the CELF/ Bruno-like family, which encodes proteins bearing highly conserved RNA recognition motif. RNA binding proteins are important elements that control normal cell functions, regulating events such as RNA processing, mRNA transport, stability and translation. VPS34 is a component of the phosphoinositide (PI) 3 kinase family which includes proteins that regulate several aspect of the cell physiology. ${ }^{17}$ Interestingly, VPS34 yeast orthologue (Vps34) has been directly involved in the pathway which regulates telomere length variation. ${ }^{18}$

In conclusion, we provide evidence from two independent cohorts for a new locus on chromosome 18q12.2 associated with short telomere length in humans. These data provide new insights into the likely pathways and mechanisms regulating telomere length in humans.

Funding: This study was funded in part by: the Wellcome Trust; NIHR (TDS), NIHR Biomedical Research Centre (grant to Guys' and St. Thomas' Hospitals and King's College London)

Competing interests: None declared.

\section{REFERENCES}

1. Olovnikov AM. A theory of marginotomy. The incomplete copying of template margin in enzymic synthesis of polynucleotides and biological significance of the phenomenon. J Theor Biol 1973;41:181-90.

2. Valdes AM, Andrew T, Gardner JP, Kimura M, Oelsner E, Cherkas LF, Aviv A, Spector TD. Obesity, cigarette smoking, and telomere length in women. Lancet 2005;366:662-4.

3. Aviv A. Telomeres and human somatic fitness. J Gerontol A Biol Sci Med Sci 2006;61:871-3

4. Andrew T, Aviv A, Falchi M, Surdulescu GL, Gardner JP, Lu X, Kimura M, Kato BS, Valdes AM, Spector TD. Mapping genetic loci that determine leukocyte telomere length in a large sample of unselected female sibling pairs. Am J Hum Genet 2006;78:480-6.

5. Vasa-Nicotera M, Brouilette S, Mangino M, Thompson JR, Braund P, Clemitson JR, Mason A, Bodycote CL, Raleigh SM, Louis E, Samani NJ. Mapping of a major locus that determines telomere length in humans. Am J Hum Genet 2004;76:147-51.

6. Mangino M, Brouilette S, Braund P, Tirmizi N, Vasa-Nicotera M, Thompson JR, Samani NJ. A regulatory SNP of the BICD1 gene contributes to telomere length variation in humans. Hum Mol Genet 2008;17:2518-23.

7. Richards JB, Rivadeneira F, Inouye M, Pastinen TM, Soranzo N, Wilson SG, Andrew T, Falchi M, Gwilliam R, Ahmadi KR, Valdes AM, Arp P, Whittaker P, Verlaan DJ, Jhamai M, Kumanduri V, Moorhouse M, van Meurs JB, Hofman A, Pols HA, Hart D, Zhai G, Kato BS, Mullin BH, Zhang F, Deloukas P, Uitterlinden AG, Spector TD. Bone mineral density, osteoporosis, and osteoporotic fractures: a genome-wide association study. Lancet 2008;371:1505-12. 
8. Valdes AM, Loughlin J, Timms KM, van Meurs JJ, Southam L, Wilson SG, Doherty S, Lories RJ, Luyten FP, Gutin A, Abkevich V, Ge D, Hofman A, Uitterlinden AG, Hart DJ, Zhang F, Zhai G, Egli RJ, Doherty M, Lanchbury J, Spector TD. Genome-wide association scan identifies a prostaglandin-endoperoxide synthase 2 variant involved in risk of knee osteoarthritis. Am J Hum Genet 2008;82:1231-40.

9. Spector TD, MacGregor AJ. The St. Thomas' UK Adult Twin Registry. Twin Res 2002;5(5):440-3.

10. Benetos A, Okuda K, Lajemi M, Kimura M, Thomas F, Skurnick J, Labat C, Bean K, Aviv $A$. Telomere length as an indicator of biological aging: the gender effect and relation with pulse pressure and pulse wave velocity. Hypertension 2001;37:381-5.

11. Abecasis GR, Cherny SS, Cookson WO, Cardon LR. Merlin-rapid analysis of dense genetic maps using sparse gene flow trees. Nat Genet 2002;30:97-101.

12. Chen WM, Abecasis GR. Family-based association tests for genomewide association scans. Am J Hum Genet 2007;81:913-26.
13. Nyholt DR. A simple correction for multiple testing for single-nucleotide polymorphisms in linkage disequilibrium with each other. Am J Hum Genet 2004; 74:765-9

14. Li J, Ji L. Adjusting multiple testing in multilocus analyses using the eigenvalues of a correlation matrix. Heredity 2005;95:221-7.

15. Aviv A. The epidemiology of human telomeres: faults and promises. J Gerontol A Biol Sci Med Sci 2008;63:979-83.

16. Kleinjan DA, van Heyningen V. Long-range control of gene expression: emerging mechanisms and disruption in disease. Am J Hum Genet 2005;76:8-32.

17. Volinia S, Dhand R, Vanhaesebroeck B, MacDougall LK, Stein R, Zvelebil MJ, Domin J, Panaretou C, Waterfield MD. A human phosphatidylinositol 3-kinase complex related to the yeast Vps34p-Vps15p protein sorting system. EMBO J 1995;14:3339-48.

18. Rog 0, Smolikov S, Krauskopf A, Kupiec M. The yeast VPS genes affect telomere length regulation. Curr Genet 2005;47:18-28. 